\title{
Pseudopithomyces chartarum associated with wheat seeds in Argentina, pathogenicity and evaluation of toxigenic ability
}

\author{
Analía Perelló • Mónica Aulicino • \\ Sebastián A. Stenglein • Román Labuda • \\ María V. Moreno
}

Accepted: 7 November 2016

C) Koninklijke Nederlandse Planteziektenkundige Vereniging 2016

\begin{abstract}
Argentina is one of the top 10 world producers and exporters of wheat. In routine surveys of wheat (Triticum aestivum L.) in Buenos Aires Province, Argentina, a new disease was observed in 2012 on seeds of wheat cv. Buck Meteoro. Symptomatic grains (black points) and leaves (chlorosis and spots) were collected during the spring of that year. The objectives of the present study were to identify the causal agent, to investigate its pathogenicity in relation to nine wheat cultivars and to identify the secondary metabolites produced by fungus. Symptomatic grains were plated on potato dextrose agar (PDA). Morphological characterization of colonies and sequencing of the ITS region after DNA extraction identified it as Pseudopithomyces chartarum. For pathogenicity tests, two different isolates, P221 and P224, were inoculated on seedlings of nine wheat
\end{abstract}

A. Perelló

Facultad de Ciencias Agrarias y Forestales,

CIDEFI-CONICET-Fitopatología, Universidad Nacional de La

Plata (UNLP), La Plata, Argentina

M. Aulicino

Facultad de Ciencias Agrarias y Forestales, Instituto Fitotècnico de Santa Catalina (IFSC), Universidad Nacional de La Plata (UNLP), Lavallol, Lomas de Zamora, Argentina

S. A. Stenglein $\cdot$ M. V. Moreno $(\bowtie)$

BIOLAB (CICBA-INBIOTEC-CONICET), Facultad de

Agronomía (UNCPBA), Microbiología, Azul, Argentina

e-mail: vmoreno@faa.unicen.edu.ar

R. Labuda

LaboVet GmbH Campus Vienna, Biocenter 3, A-1030 Wien,

Austria cultivars, which showed different disease symptoms, $\%$ of grain germination (GG), \% of grain discoloration (GD) and \% of weak seedlings (WS), suggesting different levels of response against Pseudopithomyces chartarum. Particularly B. Meteoro, Buck Guapo and Klein Proteo cultivars demonstrated major infection tolerance for GD and WS. In contrast, Sy 100 and Klein Pantera were most affected showing weakness, chlorosis, or reduced length of coleoptile, and $50 \%$ of necrotic symptoms. Pseudopithomyces chartarum isolates produced secondary metabolites including alternariol, alternariol mono-methyl ether, altertoxin I and altertoxine II. The fungus is a new pathogen of wheat in Argentina that can cause diseases on different cultivars as well as produce mycotoxins.

Keywords Pseudopithomyces chartarum · Fungi . Symptoms evaluation $\cdot$ Mycotoxins

Argentina is one of the top 10 world producers and exporters of wheat (Triticum aestivum L.) and most of its production comes from Buenos Aires Province. The area of production of cereals in Argentina is located around the Pampa and more than $80 \%$ of the Pampa's production is grains. Historically, the more important crops grown in this region were cereals, particularly wheat.

In 2012, a new disease was observed in wheat plants in Argentina. Symptomatic grains (black points) and leaves (chlorosis and spots) were collected during the spring of that year. Pieces of leaves with symptoms and 


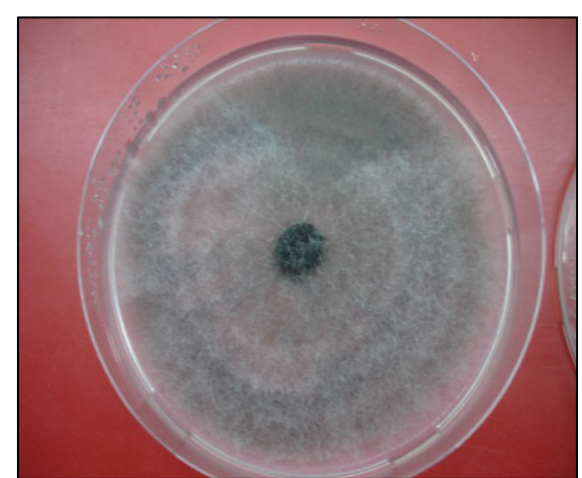

Fig. 1 P. chartarum colony on PDA media

grains were superficially disinfected and immersed in a $1 \%$ sodium hypochlorite solution for $3 \mathrm{~min}$; then they were plated on potato dextrose agar (PDA) containing $0.25 \mathrm{mg} / \mathrm{L}$ of chloramphenicol and incubated for 47 days at $25^{\circ} \mathrm{C}$ under a $12 \mathrm{~h} \mathrm{light/dark} \mathrm{cycle.}$

A sporulating, dematiaceous, mitosporic fungus was observed and transferred toPDA. Colonies had a cottony texture, first hyaline, then greyish black with dark brown multicellular conidia on branched conidiophores hardly differentiated from the vegetative hyphae (Fig. 1). The conidia were multi-celled, echinulate, brown and deeply pigmented, ellipsoidal, 18-29 × 11-18 $\mu \mathrm{m}$, with three transverse septa, and a longitudinal septum constricted at the transverse septa (Fig. 2). Morphological characteristics of the fungus fit those originally described for Pseudopithomyces chartarum (Berk. \& M. A. Curtis) J.F. Li, Ariyawansa \& K.D. Hyde (Ariyawansa et al. 2015); synonyms, Leptosphaerulina chartarum Cec. Roux; grown (Berk. \& M.A. Curtis) R.T. Moore;
Pithomyces chartarum (Berk. \& M.A. Curtis) M.B. Ellis; Sporidesmium bakeri Syd. \& P. Syd. (1914) Sporidesmium bakeri Syd. \& P. Syd. (1914) var. bakeri; Sporidesmium bakeri var. faureae Henn.; Sporidesmium bakeri var. sacchari S. Hughes, (1953); Sporidesmium chartarum Berk. \& M.A. Curtis (1874).

Two isolates obtained from culture specimens were selected at random, namely P221 for DNA confirmation and pathogenicity studies and P224 for pathogenicity studies. Culture specimens of isolates P221 and P224 (PCHW09131 and PCHW09132, respectively) were deposited in the Centro de Investigaciones de Fitopatología (CIDEFI) collection (La Plata, Buenos Aires, Argentina).

In the case of isolate P221, DNA was extracted from a pure and single conidia culture according to Stenglein and Balatti (2006). The rDNA ITS region was amplified in an XP thermal cycler (Bioer Technology Co) using primers ITS4 and ITS5 (White et al. 1990), purified using the PureLink PCR purification kit (Invitrogen) and sequenced from both the sense and antisense ends of the fragment. Sequence similarity was examined with BLASTn (Altschul et al. 1990) in the NCBI web page. The sequence (Accession number JX442978) was found to be $100 \%$ identical to P. chartarum (syn. Leptosphaerulina chartarum) (e.g. HQ607815, KC879283).

For pathogenicity testing, healthy wheat leaves of cv. B. Meteoro potted plants (third leaf emerged stage) grown under greenhouse conditions were sprayinoculated with an aqueous suspension $\left(10^{6}\right.$ conidia/ $\mathrm{mL}$ ) of 10-day-old sporulating cultures of both
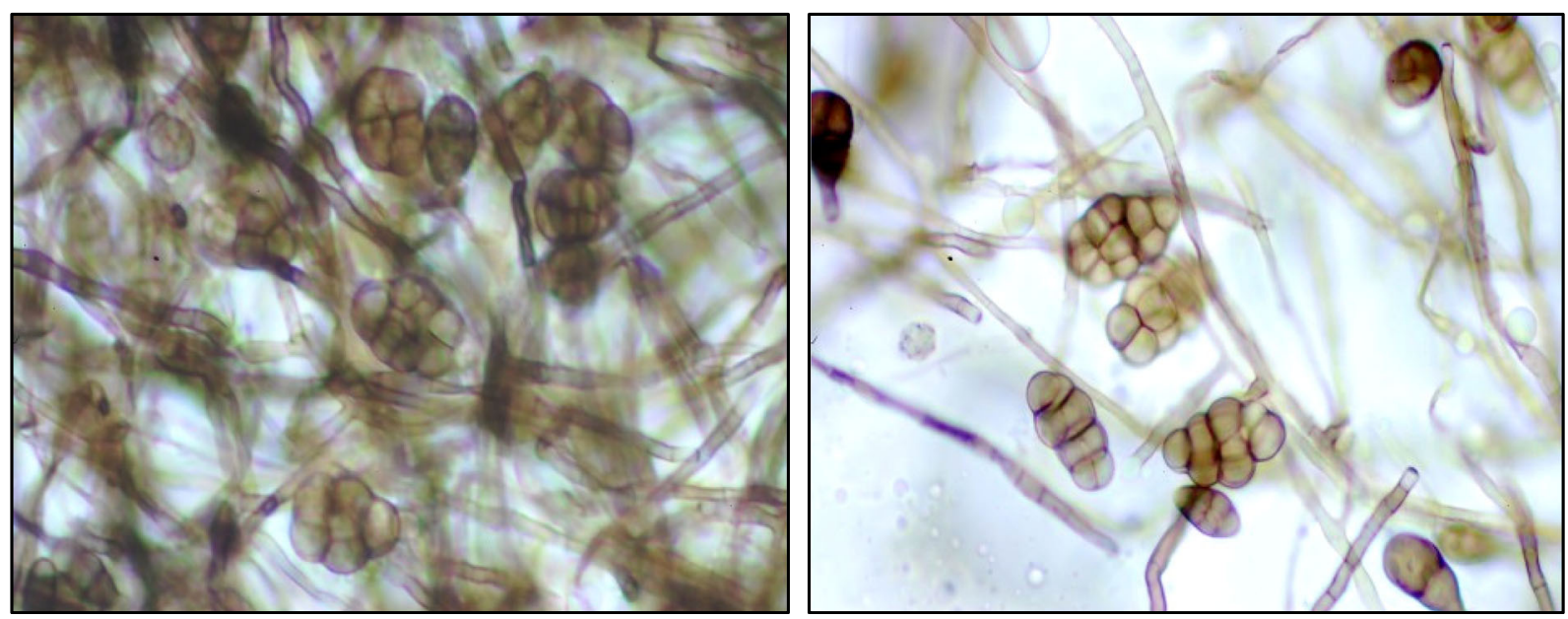

Fig. 2 Conidia of P. chartarum (400 X) Olympus CX 31 (Lactophenol Blue) 


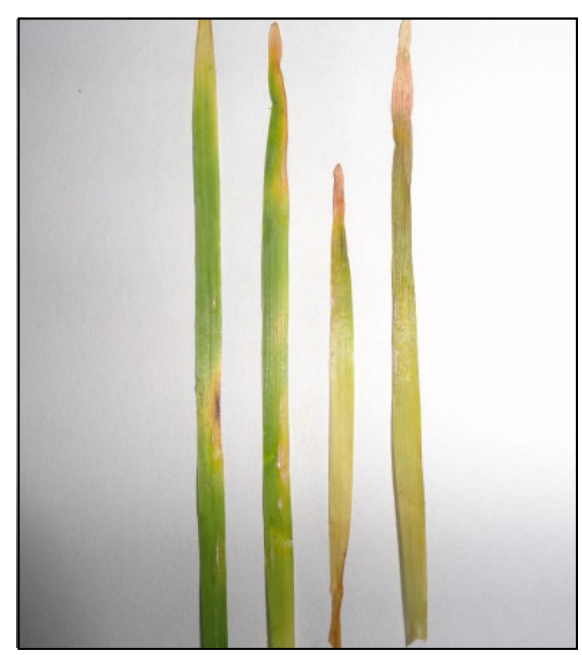

Fig. 3 Spots and chlorosis caused by P. chartarum on wheat leaves

P. chartarum isolates P221 and P224, separately. Inoculated plants and water sprayed controls were covered with polythene bags for $48 \mathrm{~h}$ and kept under natural light conditions with a mean daily temperature of $26^{\circ} \mathrm{C}$. Symptoms started developing on the inoculated plants after 7-8 days. The leaf symptoms firstly appeared as a small brown necrotic spot of light brown color, their size varied from 5 to $12 \mathrm{~mm}$ in diameter. Subsequently these spots turned into a brown elliptical lesion with the central part being grey to brown. In some cases, spots coalesced together, forming large necrotic patches (Fig. 3). Conidia of Pseudopithomyces were frequently observed on fully-developed lesions.

To determine the pathogenicity of $P$. chartarum isolates, tests were conducted following ISTA (1993) rules (blotter test) using plastic trays $(30 \times 20 \mathrm{~cm})$. Seeds of nine wheat cultivars (Buck Meteoro, Buck Taita, Sy 300, Sy 100, Buck Guapo, Buck Cl 55, Bio INTA 1004, Klein Proteo and Klein Pantera) were disinfected with $3 \%$ sodium hypochlorite for $3 \mathrm{~min}$, rinsed with distilled water and spray-inoculated with an aqueous conidial suspension of $10^{6}$ conidia/mL of both P. chartarum isolates P211 and P224, separately. Controls were sprayed with water only. For each cultivar, 50 seeds per tray were used. Four inoculated trays (IT) per cultivar and treatment were placed using a completely randomized design under greenhouse conditions. Data were taken 14 days later when symptoms developed on inoculated seeds but not in the controls (Fig. 4a, b). The fungus was re-isolated, fulfilling Koch's postulates.

Wheat cultivars inoculated with the different fungal isolates were evaluated for: $\%$ of grains germination (GG), \% of grain discoloration (GD) and \% of emerging seedlings showing weakness symptoms (WS). Percentages obtained for each inoculated cultivar tray (IT) were normalized by control means (MC) as: 1-(MC-IT). Then, non parametrical Kruskal Wallis test (statistical $\mathrm{H})$ and $P$ values using $c h i$-squared approximation were a

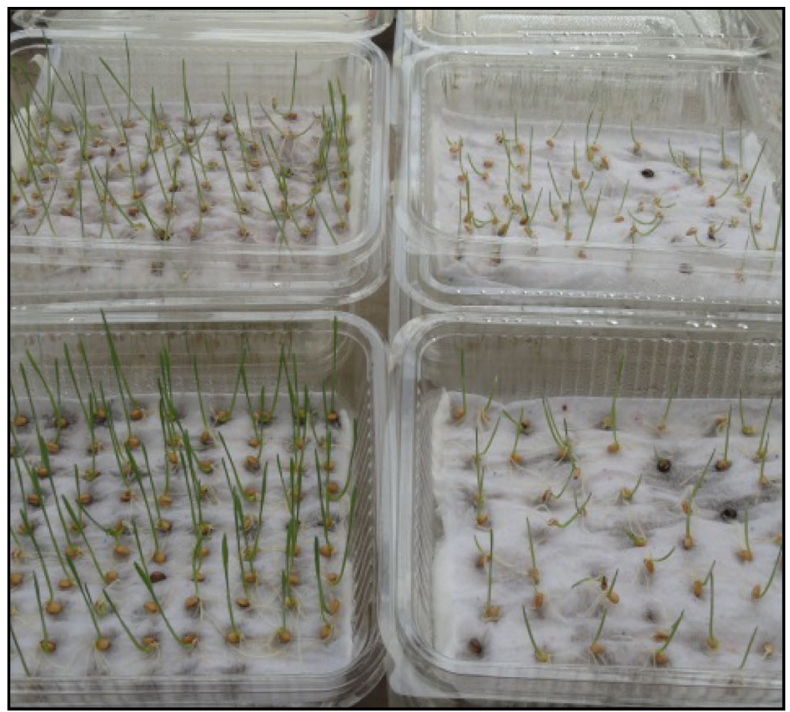

b

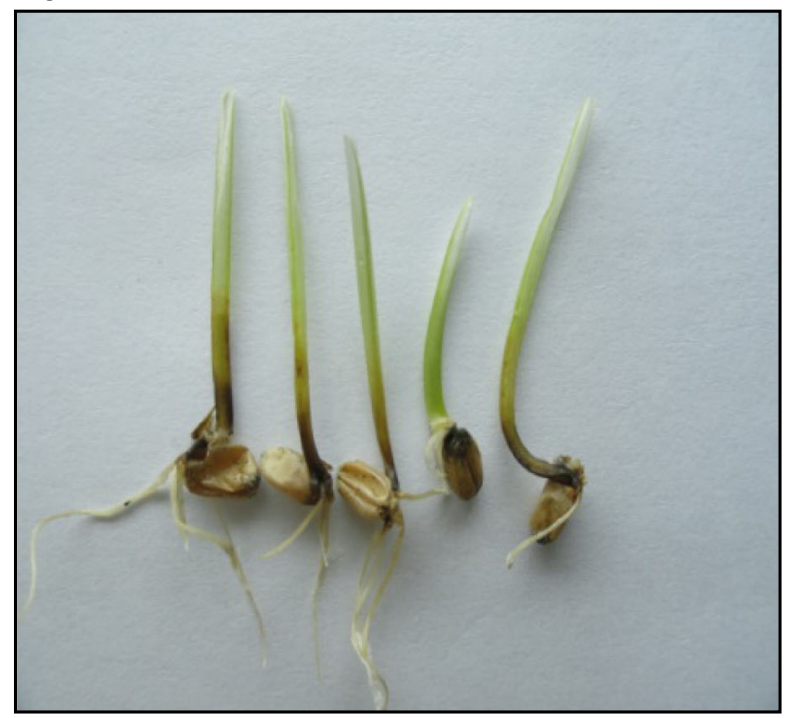

Fig. 4 a Blotter test to determine pathogenicity of $P$. chartarum on wheat seeds. b Detail of seed discoloration and coleoptile necrosis (seven days after infection) 
applied to analyze the data. This allowed us to prove differences between isolates and wheat cultivars and interactions. Pairwise comparison procedures were based in minimum significant differences between sum of ranks $(P<0.05)$ (Di Renzo et al. 2012); the means and standard errors of the original values were calculated.
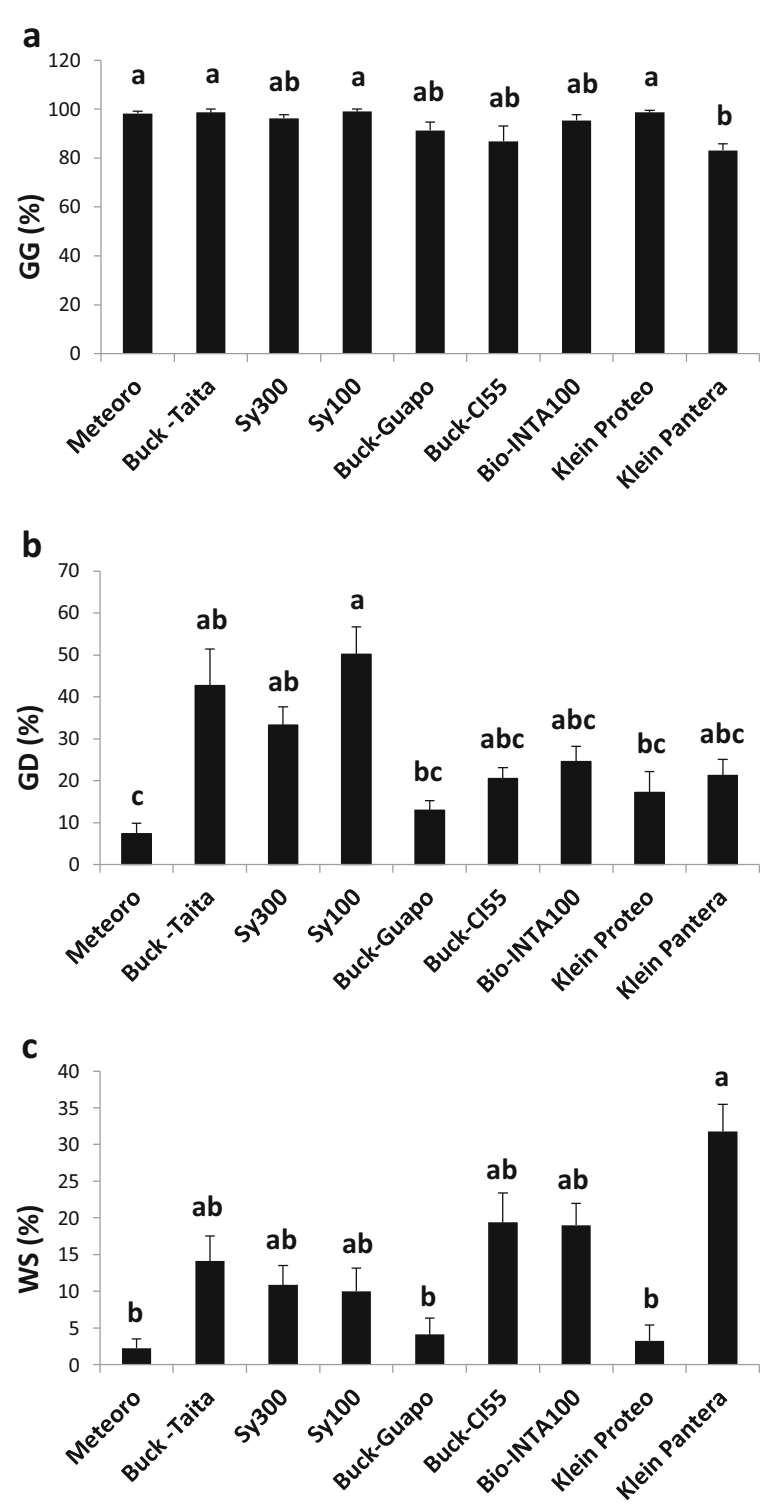

Fig. 5 Means and standard errors of nine wheat cultivars inoculated with P. chartarum (mean between isolates P221 and P224) for percentage of: a grain germination (GG); b grain discoloration (GD); and $\mathbf{c}$ weakness of seedlings (WS). The comparison was based on minimum significant differences between sum of ranks. Different letters indicate significant differences between cultivars $(P<0.05)$
Figure 5 shows differences in the nine wheat cultivars (calculated means averaging over the isolates) in percentages of GG, GD and WS, suggesting different levels of response in wheat against $P$. chartarum. Except for cv. K. Pantera, GG was not severely affected by the fungus (Fig. 5a). However, the fungus infection caused grain discoloration (GD), particularly in cv. Sy 100, which reached $50 \%$ of seed surface area (Fig. 5 b). Seedlings emerged after the seed inoculation with P. chartarum showed weakness, chlorosis of coleoptile, or reduced length (Fig. 5c), particularly cv. K. Pantera.

When P221 and P224 means were compared nonsignificant differences between isolates $(P<0.05)$ were found for $\mathrm{GG}(\mathrm{H}=0.106, P=0.74)$, GD $(\mathrm{H}=2.86$, $P=0.09)$ and WS $(\mathrm{H}=0.37, P=0.54)$. However, presence of interaction "cultivar $\mathrm{x}$ isolates strain" was detected for GD and WS traits but it was absent for GG (figure not showed). Interactions comparison demonstrated the variation of response between cultivars inoculated with the different isolates when these were analyzed separately (Fig. 6). Cultivars Sy 100 and B. Taita showed the highest values of GD when they were inoculated with both isolates and had significant differences from cv. B. Meteoro inoculated with strain 221, which showed the minimum GD (Fig. 6a). Cultivar K. Proteo inoculated with isolate P221 and cv. B. Guapo inoculated with P224, showed no weak-seedling, indicating a better resistance when compared with cv. K. Pantera inoculated with the isolate P221 (Fig. 6b), with the maximum WS.

Isolates P221 and P224 of P. chartarum were analysed for mycotoxin production by using the multidetection method described by Tančinová and Labuda (2009) and Vishwanath et al. (2009). P. chartarum infected wheat seeds $(5 \mathrm{~g})$ were mixed with $5 \mathrm{~mL}$ of extraction solvent acetonitrile/water/acetic acid (79/20/ $1 \mathrm{v} / \mathrm{v} / \mathrm{v}$ ) and stirred for $10 \mathrm{~min}$ followed by ultrasonication for more than $10 \mathrm{~min}$ per sample. The colonies were grown on yeast sucrose extract agar (YES) at $25^{\circ} \mathrm{C}$ in darkness for 14 days to obtain the inocula following the method described by Samson et al. (2002). One hundred $\mu \mathrm{L}$ of the extract was filtered, dried, redissolved in $1000 \mu \mathrm{L}$ of water-acetonitrile $(1 / 1 v / v)$ and applied to a Liquid chromatography coupled with tandem mass spectrometry (LC-MS/MS) system. The LC-MS/MS analysis was done on a QTrap 4000 (AB Sciex, Foster City, CA, USA) equipped with a Turbolon Spray electrospray ionization (ESI) source and connected to an Agilent 1100 HPLC (Agilent, 
Fig. 6 Means and standard errors of nine wheat cultivars inoculated with strains 221 and 224 of

$P$. chartarum for: a grain discoloration (GD); and $\mathbf{b}$ weakness of seedlings (WS). The comparison was based on minimum significant differences between sum of ranks. Different letters indicate significant differences between cultivars $(P<0.05)$
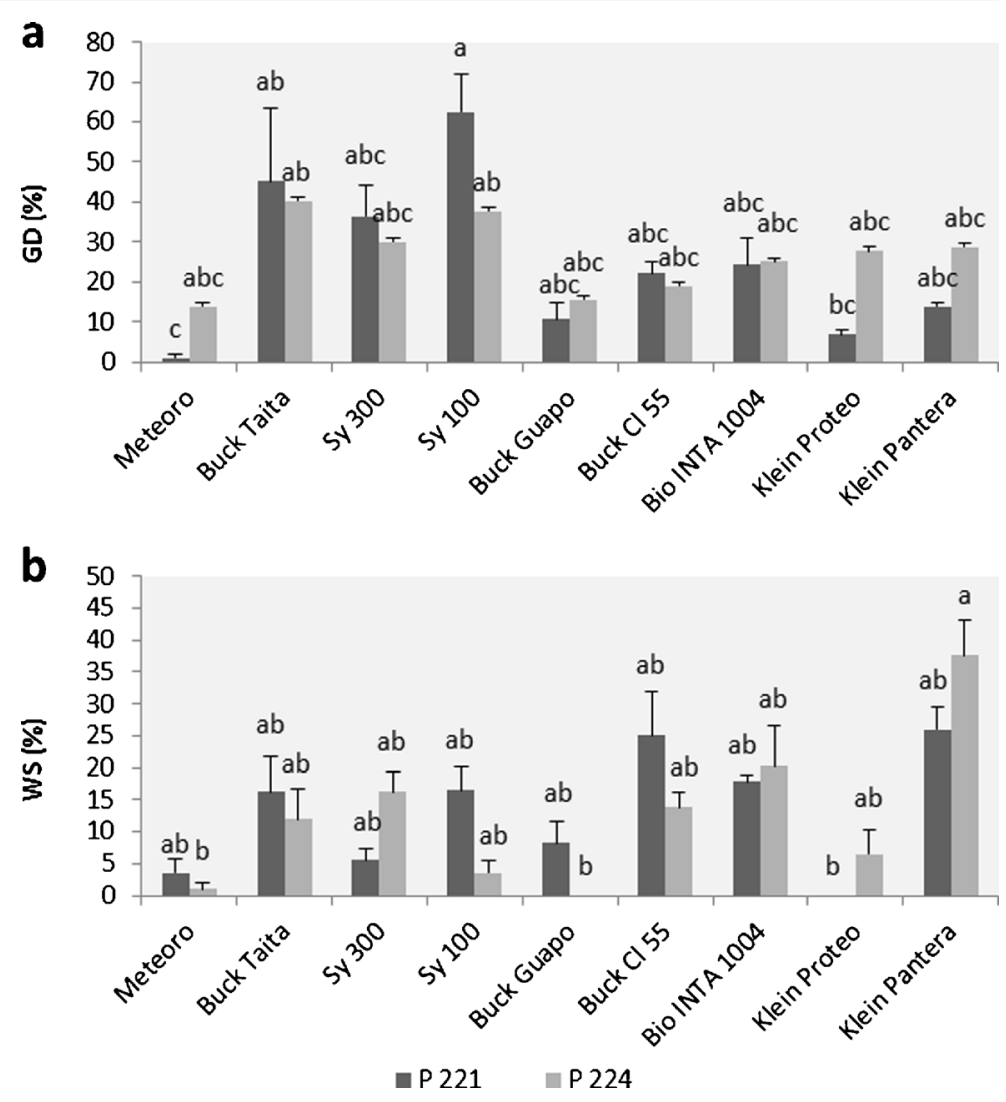

Waldbronn, Germany). The separation was done on a $150 \times 4.6 \mathrm{~mm}$ i.d. Gemini C18 column equipped with a $4 \times 3 \mathrm{~mm}$ security guard cartridge (all from Phenomenex, Torrance, CA, USA). The chromatographic methods as well as mass spectrometric parameters for the investigated analytes are as described by Vishwanath et al. (2009).

Four mycotoxins were detected (Table 1), namely alternariol $(\mathrm{AOH})$, alternariol mono-methyl ether (AME), altertoxin I (ATX-I) and altertoxin II (ATX-II). These toxins are mycotoxins produced also by Alternaria species that cause plant diseases on many crops such as wheat and other cereals. Particularly,

Table 1 Toxin production $(\mathrm{mg} / \mathrm{kg})$ of $P$. chartarum, isolates P221 and P224, collected from wheat seeds

\begin{tabular}{lllll}
\hline Fungal isolates & AOH & AME & ATX-I & ATX-II \\
\hline P221 & 0.20 & 0.24 & 0.21 & 0.10 \\
P224 & 0.37 & 0.42 & 0.29 & 0.26 \\
\hline
\end{tabular}

$A O H$ alternariol, $A M E$ alternariol monometyl ether, $A T X-I$ altertoxin I, ATX-II altertoxin II
$\mathrm{AOH}, \mathrm{AME}$ and altertoxins among others, are genotoxic in vitro and/or fetotoxic in rats (EFSA 2011). Generally, these toxins are found in grains and grain-based products. There is limited information in Argentina about the toxic effects of these toxins on animals and humans and occurrence data in feed, in order to assess the health risk for different species.

To the knowledge of the authors the disease does not have a formal name. Pseudopithomyces chartarum is known to cause leaf spot diseases of various plants including medicinal plants (Jonardhanan 2002), grasses (Varga and Fischl 2006), cereals (Tóth et al. 2007) and legumes (Amaral et al. 1976; Ponappa 1977; Russomanno et al. 1985; Eken et al. 2006). Pseudopithomyces chartarum has been recorded as a wheat pathogen in Europe, Tanzania and Brazil (Dingley 1962; Farr et al. 2007; Tóth et al. 2007). However, this is, to the knowledge of the authors, the first report of this fungus causing disease on wheat in Argentina. Pseudopithomyces chartarum constitutes a potential threat considering its production of toxins. It has been reported that some $P$. chartarum isolates produce a hepatoxic mycotoxin named sporidesmin 
(Houbraken et al. 2006), which causes skin damage to sheep, goats and cattle (Bezille et al. 1984; Collin et al. 1998; Farr and Rossman 2010). None of the two Argentinian isolates found in the present work produced sporidesmin (results not shown), but they produced other dangerous secondary metabolites (like AOH, AME and altertoxins) according EFSA (2011). Interestingly, Licoff et al. (2008) isolated the fungus from forage and grasses in Argentina. The authors highlighted the great variability of $P$. chartarum in sporidesmin production, from 0 to $100 \%$ according the isolates and the agroecological area sampled.

This is the first description of the occurrence of Pseudopithomyces chartarum causing disease on wheat in Argentina. The discovery is relevant because this disease can cause several losses on wheat-growing areas of Argentina and the fungus produces mycotoxins, which is an additional threat.

\section{References}

Altschul, S. F., Gish, W., Miller, W., Myers, E. W., \& Lipman, D. J. (1990). Basic local alignment search tool. Journal of Molecular Biology, 215, 403-410.

Amaral, R. E. M., Nazário, W., \& Andrade, S.O. (1976). Ocorrência do fungo Pithomyces chartarum (Berk. \& Curt.) Ellisem grãos e forrageiras no Brasil. Proceedings of the Congreso Brasileiro de Fitopatología Campinas, San Pablo, Brazil, p. 82 (Abstr.).

Ariyawansa, H., Hyde, K., Jayasiri, S., \& Chen, X. H. (2015). Fungal diversity notes 111-252-taxonomic and phylogenetic contributions to fungal taxa. Fungal Diversity, 27-274. doi:10.1007/s13225-015-0346-5.

Bezille, P., Braun, J. P., \& LeBars, J. (1984). First identification of facial eczema in Europe: epidemiological, clinical and biological aspects. Recueil de Medecine Veterinaire, 160, 339347.

Collin, R. G., Odriozola, E., \& Towers, N. R. (1998). Sporidesmin production by Pithomyces chartarum isolates from Australia, Brazil, New Zealand and Uruguay. Mycological Research, 102, 163-166.

Di Renzo, J. A., Casanoves, F., Balzarini, M. G., Gonzalez, L., Tablada, M., \& Robledo, C. W. (2012). InfoStat vers. 2012. InfoStat group, Facultad de Ciencias Agropecuarias, Universidad Nacional de Córdoba: Argentina.

Dingley, J. (1962). Pithomyces chartarum, its occurrence morphology, and taxonomy. New Zealand Journal of Agricultural Research, 5, 49-61.

EFSA (2011). Scientific opinion on the risks for animal and public health related to the presence of Alternaria toxins in feed and food. European Food Safety Authority. EFSA Journal, 9(19), 2407.
Eken, C., Jochum, C. C., \& Yuen, G. Y. (2006). First report of leaf spot of smooth bromegrass caused by Pithomyces chartarum in Nebraska. Plant Disease, 90, 108.

Farr, D. F., \& Rossman, A. Y. (2010). Fungal databases, systematic mycology and microbiology laboratory. USDA-ARS. http://nt.ars-grin.gov/fungaldatabases. Accessed 23 September 2015.

Farr, D. F., Rossman, A. Y., Palm, M. E., McCray, E. B. (2007). Fungal databases, systematic botany and mycology laboratory, ARS, USDA. Retrieved March 5, 2007, from http://nt. arsgrin.gov/fungaldatabases/.

Houbraken, J., Frisvad, J. C., \& Samson, R. A. (2006). Sporidesmin production by Pithomyces. Proceedings of the 8th International Mycological Congress, Cairns, Australia, p. 20 (Abstr.).

ISTA (1993). International rules for seed treating. International Seed Testing Association, 13, 200-520.

Jonardhanan, K. K. (2002). Diseases of major medicinal plants. Daya Publ. House, Delhi: India.

Licoff, N., Khalloub, P., Diab, S., Cantón, G., Odeón, A., \& Odriozola, E. (2008). Evaluación toxicológica de Pithomyces chartarum en Argentina. Revista de Medicina Veterinaria, 89, 9-12.

Ponappa, K. M. (1977). New record of fungi associated with Cannabis sativa. Journal of Mycology and Plant Pathology, 7, 139.

Russomanno, O. M. R., Amaral, R. E. M., Malavolta, V. M. A., Alcantara, V. B. G., \& Schammass, E. A. (1985). Ocorrência do fungo Pithomyces chartarum (Berk. \& Curt.) M. B. Ellis em forrageiras pastoreadas por bovinos. Revista de Agricultura Piracicaba, 60, 249-265.

Samson, R. A., Hoekstra, E. S., Frisvad, J. C., \& Filtenborg, O. (Eds.) (2002). Introduction to food-and air borne fungi (6th ed.). Utrecht: Centraal Bureau voor Schimmelcultures.

Stenglein, S. A., \& Balatti, P. A. (2006). Genetic diversity of Phaeoisariopsis griseola in Argentina as revealed by virulence and molecular markers. Physiological and Molecular Plant Pathology, 68, 158-167.

Tančinová, D., \& Labuda, R. (2009). Fungi on wheat bran and their toxinogenity. Annals of Agricultural and Environmental Medicine, 16, 325-331.

Tóth, B., Csosz, M., Dijksterhuis, J., Frisvad, J. C., \& Vagra, J. (2007). Pithomyces chartarum as a pathogen of wheat. Journal of Plant Pathology, 89, 405-408.

Varga, Z., \& Fischl, G. (2006). Pathogenic fungal species isolated from leaves and seeds of smooth brome (Bromus inermis Leyss.). Communications in Agricultural and Applied Biological Sciences, 71, 1103-1108.

Vishwanath, V., Sulyok, M., Labuda, R., Bicker, W., \& Krska, R. (2009). Simultaneous determination of 186 fungal and bacterial metabolites in indoor matrices by liquid chromatography/tandem mass spectrometry. Analytical and Bioanalytical Chemistry, 395, 1355-1372.

White, T. J., Bruns, T., Lee, S., \& Taylor, J. (1990). Amplification and direct sequencing of fungal ribosomal RNA genes forphylogenetics. In M. A. Innis, D. H. Gelfand, J. Sninsky, \& T. J. White (Eds.), PCR protocols: a guide to methods and applications (pp. 315-322). Academic Press, San Diego, CA: USA. 